\title{
Contradictions and Interventions in Health IS
}

\author{
A Framework Based on Activity Theory
}

\author{
Andy Weeger $\cdot$ Heinz-Theo Wagner $\cdot$ Heiko Gewald $\cdot$ Tim Weitzel
}

Received: 30 March 2017/Accepted: 17 December 2020/Published online: 21 April 2021

(C) The Author(s) 2021

\begin{abstract}
The study analyzes data collected in two case studies in the healthcare industry, which is characterized by a variety of social and technical elements forming an activity system where all elements interact with each other. The findings indicate that many problems emerging during the implementation of a health information system can be traced back to contradictions between elements of the activity systems that are created or amplified by the new IS. The authors find that some contradictions are latent and become salient when introducing a new IS, while other contradictions are (unintentionally) newly created. Also, the study shows that contradictions are more complex than hitherto assumed and often concern more than two elements of a healthcare activity system. In a similar vein, effective interventions geared toward countering these contradictions are found to account for additional complexity while not always achieving their goal. Drawing on activity theory, the authors develop a framework to coherently synthesize the findings. The study can help increase the understanding of the IS's role within an
\end{abstract}

Accepted after five revisions by Jens Dibbern.

A. Weeger $(\bowtie) \cdot$ H.-T. Wagner · H. Gewald

Center for Research On Service Sciences, Neu-Ulm University

of Applied Sciences, Wileystraße 1, 89231 Neu-Ulm, Germany

e-mail: andy.weeger@hnu.de

H.-T. Wagner

e-mail: heinz-theo.wagner@hnu.de

H. Gewald

e-mail: heiko.gewald@hnu.de

T. Weitzel

Department for Information Systems and Services, University of

Bamberg, An der Weberei 5, 96047 Bamberg, Germany

e-mail: tim.weitzel@uni-bamberg.de activity system and help guide IS implementation projects aimed at avoiding unintended consequences.

Keywords Health information systems (HIS) · Postimplementation · Contradictions · Activity theory · Hospital · Healthcare

\section{Introduction}

Given that health is a definitively important topic for almost all individuals, healthcare systems and organizations are of utmost importance to society. It is anticipated that digitizing patient care will have a tremendous impact on the quality, safety, affordability, and accessibility of healthcare services (Agarwal et al. 2010). In particular, the diffusion of health information systems (HIS) is expected to increase quality of care (Sharma et al. 2016), decrease costs (Bardhan and Thouin 2013), and enable a more targeted application of therapies (Yaraghi 2015). However, in reality, implementing an HIS is a very challenging process that often ends with critical post-implementation issues such as dysfunctional workflows and resistance that inhibit the realization of goals such as better quality of care and greater efficiency (Strong et al. 2014; Oborn et al. 2011; Cresswell and Sheikh 2013; Goh et al. 2011).

These characteristics seem to arise from the unique complexities of the healthcare context that are reflected in several contradictions - for example, improving patients' health status versus improving hospital productivity, or time devoted to administrative efforts versus time dedicated to patient care (see e.g., Sarker et al. 2019; Mintzberg 1979; Fichman et al. 2011). Likewise, healthcare and healthcare actors are primarily driven by humanistic goals, where patients' health is seen as the most important good 
(Allwood and Selart 2010); nevertheless, instrumental goals like efficiency and productivity are becoming increasingly important (Sarker et al. 2019). Accordingly, as in other contexts, the objectives, values, and priorities of different stakeholders in healthcare are not independent; rather, they determine, influence, and sometimes contradict each other (Benbya et al. 2020). To avoid post-implementation issues in complex environments such as healthcare, the literature indicates that the interrelations between different and sometimes conflicting goals, multiple stakeholders, the processes in place, and the influence of information systems on all of these aspects need to be considered (Karanasios and Allen 2013; Allen et al. 2013b).

Post-implementation issues are an important topic for IS research because HIS regularly disappoint users and stakeholders (Cresswell and Sheikh 2013). Post-implementation issues often arise because the IS contradicts established behavior, organizational practices, and expected performance (Berente et al. 2016). The latter may cause additional issues and may inhibit realizing the original goals of IS implementation (Boudreau and Robey 2005).

Despite the existing research on post-implementation issues related to HIS (Cresswell and Sheikh 2013; Kilsdonk et al. 2016), there is still a lot to learn about how IS interacts with multiple, interconnected, diverse, and mutually dependent contextual elements (Benbya et al. 2020), and how these interactions may cause post-implementation issues (Avgerou 2001; Dwivedi et al. 2015; Williams and Pollock 2012). In this paper, we note that research has hitherto mainly focused on issues that show up in the post-implementation phase and neglects the fact that there might already be troublesome issues amongst contextual elements prior to the implementation of the new IS that have not yet manifested as problems. Hence, we assume that there are latent issues that may be present but have not yet become virulent (Smith and Lewis 2011) and only manifest as problems once the IS has changed the multifaceted contextual relationships. We also note that extant research mostly investigates only the interaction of two contextual elements and their potential to cause postimplementation problems. Well-studied relationships are, for instance, those occurring between IS and users (Boudreau and Robey 2005), IS and organizations (Berente et al. 2016; Rohner 2013) and IS and multidisciplinary practices (Abouzahra et al. 2015; Oborn et al. 2011). However, the manifestation of post-implementation issues in the healthcare context requires a deeper understanding of how IS interact with the many elements contributing to the social and technical complexities of healthcare work (Lluch 2011). Thus, this study extends the current literature by investigating more than a simple dyad of elements in order to increase the understanding of both the manifestation of post-implementation issues and the interventions required for healthcare digitalization. Considering that post-implementation issues might be the consequence of more than two conflicting elements, interventions aimed at such post-implementation issues should also consider more than two elements.

To better understand the interactions between an HIS, its multiple contextual elements, and its post-implementation issues, we pose the following research questions: (RQ1) Which post-implementation issues can be attributed to contradictions in the network of interactions between an HIS and various elements of the healthcare context? (RQ2) What management interventions are capable of solving or mitigating these contradictions?

Supported by contemporary research in IS (Allen et al. 2013a), we maintain that activity theory (AT) is especially suited for our purpose of tackling the interaction of multiple elements, namely, the IS and the elements that define the context in which an IS is implemented. Thus, our study applies AT, particularly its concept of contradictions within activity systems, which has not been fully explored thus far (Groleau et al. 2012). AT views collective activities that are geared toward realizing intended outcomes as being performed in systems of various complexly interacting and partly contradictory elements (Engeström and Punamäki 1999; Karanasios and Allen 2014). These systems are called activity systems. AT further proposes that the functionality of an activity system, and thus the ability to achieve intended outcomes, is dependent on the interactions of multiple elements; the IS is only one of these elements (Strong and Volkoff 2010; Berente et al. 2016). In addition, AT anticipates that elements within the system can and will contradict each other. These contradictions oppose "the overall motive of the system, the aim or purpose that subjects within the system are individually or collectively striving toward" (Allen et al. 2013a, p. 840). Contradictions "manifest themselves as problems, ruptures, breakdowns, and clashes" (Kuutti 1999, p. 34) and impede the realization of intended outcomes, just as postimplementation issues do.

To answer our research questions, we analyzed activity systems by identifying and understanding the different elements, the contradictions in the systems that caused the post-implementation issues observed, and the management interventions needed to mitigate these issues. The empirical data stems from two HIS implementation projects in a large German teaching hospital. Before data collection started, we connected AT to the extant research on postimplementation issues to familiarize ourselves with the study context and developed initial assumptions about the relations among the elements of the activity system investigated, potential contradictions between elements, and interventions designed to counter contradictions. By 
iteratively interpreting our data and refining the theoretical concepts, we developed a coherent explanation of contradictions between elements that emerged during and after the implementation of the HIS. Moreover, we propose a theoretically grounded explanation of the effectiveness of management interventions intended to restabilize the activity system by realigning the elements.

\section{Theoretical Foundation}

AT sees contradictions within collective human activities, where "equilibrium is an exception and tensions, disturbances and local innovations are the rule" (Cole and Engeström 1993), as the driving force for the advancement of human activities (Engeström 2001). In an economic context, collective activities refer to processes within an organization (e.g., a hospital) where various parties and tools such as information technology are involved (e.g., patient care) (Albert et al. 2015). AT views the enhancement of these activities (e.g., by means of digitization) as a process of adapting the social and material resources through which they are enacted in such a way that emergent and historically accumulated contradictions are resolved (Cole and Engeström 1993).

In this study, we are interested in how inpatient healthcare activities develop by means of implementing digital tools. As already indicated, the context of healthcare delivery in hospitals is rather complex; healthcare provision is, for example, multidisciplinary in nature (i.e., multiple actors that are directly involved or interested), characterized by strict hierarchies (i.e., complex, sometimes bureaucratic division of labor), and subject to extensive regulation (i.e., multiple, partly conflicting rules and regulations) (Rohner 2013). In the face of such contextual complexities, healthcare actors seek highly reliable digital tools that are adaptable to local variations of other social and material elements that define the context of healthcare activities (Fichman et al. 2011). Prior research has shown that healthcare information systems (HIS) that do not fit to their context may be used differently than designed (Oborn et al. 2011) and thus contribute to the development of critical issues that obstruct the functioning of healthcare activities by, for instance, disrupting routines or limiting the flexibility of healthcare actors (see e.g., Goh et al. 2011). Strong et al. (2014) further show that the process through which the introduction of an HIS to healthcare activities influences the organization is nondeterministic and multilevel, often leading to ongoing postimplementation issues. Unsurprisingly, much prior research has identified the difficulties involved in implementing HIS as a "one size fits all" proposition (Oborn et al. 2011; Poon et al. 2004). However, some scholars suggest that the design and functionalities of an HIS and evolved practices should be carefully aligned (Goh et al. 2011; Ammenwerth et al. 2006) so that the HIS can meet the complexities of the socio-organizational context. These adjustments require the consideration of different perspectives and needs (Heeks 2006; Cresswell and Sheikh 2013).

AT frames the elements that define the complexities of collective human activities and the different perspectives and needs of actors in a coherent system. This system is called the activity system, which AT introduces as a basic unit of analysis and analytical framework that allows for the analysis of the social- and time-dependent context of human activities and their enhancement (Engeström 2001). The activity system comprises seven interdependent elements that are described and contextualized to the healthcare context below.

The activity system is organized around the object, which refers to a physical or cognitive entity that is under construction, moving from a "problem space" to a desired outcome (Engeström 2001, 1999). In healthcare, the object of most activities is the health of the patient under the care of medical providers such as doctors and nurses. The object drives the collective activity and takes shape and acquires its value by being transformed by subjects to achieve the outcome. The intended outcome is an improved or at least not declining health status. Nurses and physicians are part of the medical staff that forms the subjects of our activity system. Their actions and interactions are ultimately patient focused. Among other elements, these actions are mediated by the HIS and the medical devices used to facilitate the outcome (the tools), explicit regulatory requirements and the implicit norms and culture that govern the work (the rules), a strict hierarchy, professional autonomy that governs how tasks are distributed and how roles and responsibilities are defined (the division of labor), and the wider community of practitioners that revolve and evolve around the object, including hospital administrators, insurance companies, and policy makers (see Fig. 1).

According to AT, the object always involves tensions between its use value (i.e., the needs that are fulfilled by transforming the object) and its exchange value (i.e., the commercial value of the activity). Over time, activity systems, i.e., the elements and their interrelations, evolve so that tensions are mitigated so that the object continues driving the collective activity and acquires both use and exchange value by being transformed by the subject (Engeström 1999). However, if elements are changed, or if new elements are introduced into these systems, as is the case with IS implementation, tensions within the historically evolved activity system may arise. These changes are set in place to better realize the use and/or exchange value of the object but they also introduce new perspectives and 


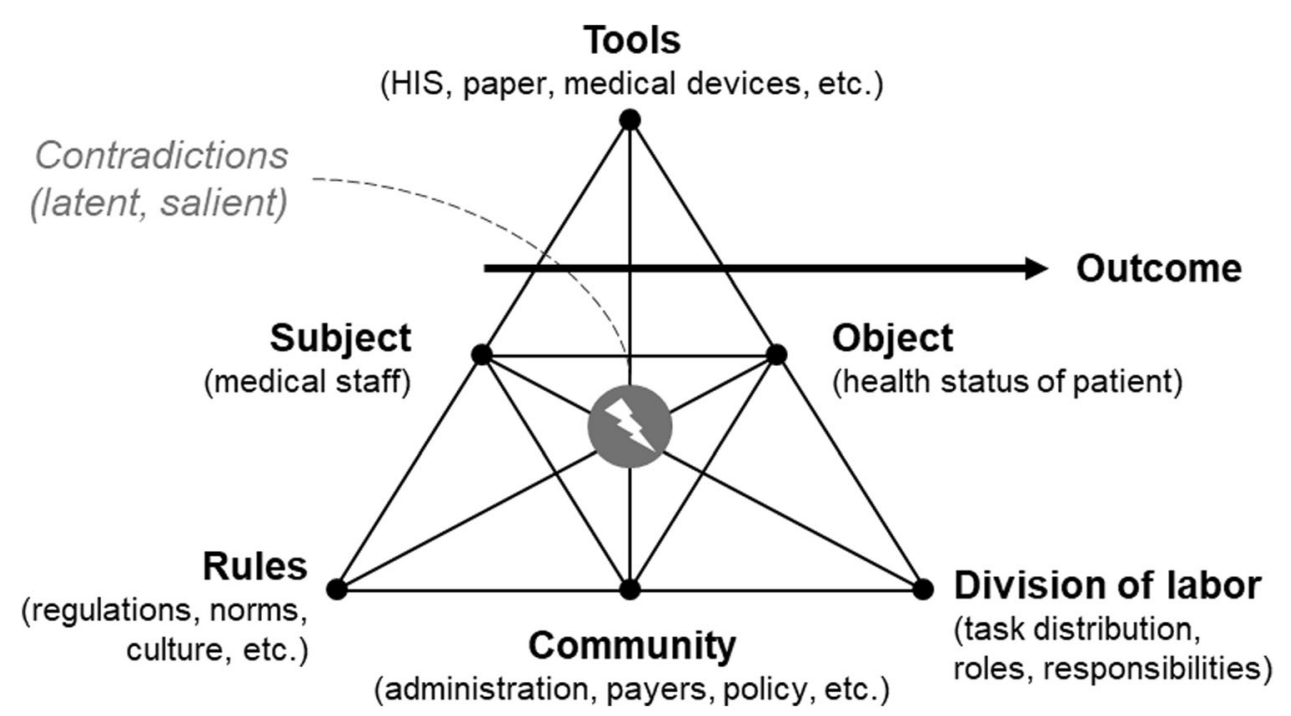

Fig. 1 General healthcare activity system

interests within the activity system that may amplify or contradict existing ones (Groleau et al. 2012). Thus, the result of such changes may be an activity system that is not well aligned but rather characterized by conflicting elements and troubled interrelations. This is what AT calls contradictions. Contradictions "within elements, between them, between different activities, or between different developmental phases of a single activity" are those forces that destabilize activities and reveal inefficiencies. They "manifest themselves as problems, ruptures, breakdowns, and clashes" (Kuutti 1999) by opposing "the overall motive of the system, the aim or purpose that subjects within the system are individually or collectively striving toward" (Allen et al. 2013a).

An inherent contradiction in the healthcare context relates to humanistic goals that are tied to the use value of an activity versus instrumental goals that are tied to its exchange value. Healthcare and healthcare actors are primarily driven by humanistic goals defining patient health as the most important good, and treatment often requires a long-term health trajectory rather than efficiently fighting an isolated disease (Allwood and Selart 2010). Nevertheless, instrumental goals like efficiency and productivity become increasingly important (Sarker et al. 2019), creating a contradiction between these goals.

Modifying elements in the activity system may lead to contradictions within the activity system, which may manifest as post-implementation issues that destabilize the activity and expose inefficiencies. For instance, implementing an HIS as a tool to improve a hospital's reimbursement process may accentuate the contradiction between monetary motives and the humanistic goals related to subjects' healthcare activities, which, in turn, may lead to resistance jeopardizing the activity system's intended outcome. Combining the activity theoretical concept of contradictions (Groleau et al. 2012) with the idea of latent and salient tensions, as noted by Smith and Lewis (2011), we theorize that, in addition to new contradictions that are caused by changes to the activity system, there may also be contradictions within activity systems that are present before the implementation of a new IS begins. The activity system may be able to mitigate these contradictions, preventing them from surfacing (e.g., by means of workarounds or provisional tools). Thus, these contradictions will be unperceived or ignored (i.e., latent) as long as the activity system creates "an interdependent, complementary duality" (Wareham et al. 2014, p. 1199) in which two options are not mutually exclusive. Jay (2013, p. 137) refers to this as a "latent organizational paradox" involving contradictory interpretive schemes and an ambiguity in terms of whether certain outcomes represent successes or failures. However, there is a risk that these dualistic mechanisms will not work when one or more elements of the activity system and thus the overall interrelations change. We theorize that if changes to the activity system render this duality impossible or dissolve the ambiguity, latent contradictions become salient. Becoming salient means that these contradictions surface and can be experienced and observed as post-implementation issues (Smith and Lewis 2011). Thus, the modification of one element in the activity system (i.e., adding an HIS to the tools) can cause latent contradictions between other elements of the activity system to surface. These then salient contradictions need to be approached by management intervention to keep the system functional.

To avoid such issues, existing contradictions within the activity system need to be identified and new contradictions need to be anticipated. To avoid post-implementation 
issues, the activity system thus must be knowledgeable of tools employed in collective activities and of potential contradictions that may occur, particularly concerning rather invisible aspects such as rules and the division of labor, including the tacit knowledge they carry. Ultimately, this enables actors to proactively take interventions to avoid or manage post-implementation issues caused by purposeful adaptations to the HIS or other elements of the affected activity systems. Conversely, we also expect that significant obstructions of work activities indicate that the activity system was unable to deal with adaptations of elements affected by IS implementation.

\section{Methodology and Research Cases}

We conducted two in-depth case studies within a single organization. We chose the case study methodology because case studies are capable of providing an ample description of complex phenomena in the context of a specific time and place (Yin 2009), which enabled us to identify the characteristics of the activity system. We chose to analyze two cases to increase the robustness of the findings in terms of the goals of the study (Maxwell 2013).

Following a literal replication strategy, we purposefully selected two cases within a single hospital, as we expected the cases to yield similar results (Yin 2009; Eisenhardt 1989). The two cases allowed us to look for similarities and variations within the phenomena under investigation (i.e., characteristics of the activity system, contradictions, and interventions) while guaranteeing some degree of unit homogeneity (Gerring 2008). In that regard, studying two cases within a single hospital ensured that the activity systems would be as comparable as possible. Nevertheless, the cases were chosen for theoretical rather than statistical reasons (Eisenhardt 1989).

In line with Eisenhardt's (1989) recommendation for case study research, we framed our research questions in light of prior research. We engaged in an iterative process of considering theoretical concepts from extant literature, developing assumptions about the nature and content of the phenomena under investigation and comparing the patterns identified with our theoretical deliberations to enhance our theoretical perspective (Walsham 1995). Here, the interplay between the literature and the empirical data of the first case study (i.e., the episodes observed) led to an initial version of the activity theoretical model. The second case study was then conducted to refine and corroborate the explanatory value of our theoretical insights (see also Fig. 2). Across the two cases, we looked for similar and contrasting illustrations of all contradictions within the activity systems we identified for the case study data. Moreover, we analyzed these illustrations for similarities and variances in the characteristics of the activity systems and the interventions during the post-implementation phase.

\subsection{Research Cases}

The research site for both case studies was a large university teaching hospital in Germany consisting of multiple clinics and specialist departments. The hospital employs almost 10,000 people and provides healthcare services for about 400,000 patients annually. Between 2014 and 2016, we had the opportunity to observe two major HIS implementation projects, which we used as our two cases: the implementation of a PDMS (patient data-management system) for critical care units ("CareSys") and a PDMS for general wards, i.e., hospital departments ("PatientDoc"; we only observed the implementation at one ward, the Addictive Psychiatry ward). Both projects were carried out to address changing regulatory requirements and increased cost pressures.

PDMS guide and support clinical workflows by enabling healthcare professionals to collect and access patient-related data such as vital parameters and information about the course of treatment and patient health status (Fretschner et al. 2001). Besides tracking patients' health status, treatment-related data such as nursing tasks, drug orders, and medication plans, etc., can be managed within these HIS. Moreover, PDMS also provide support for clinical decision-making by aggregating, analyzing, and visualizing available data. They also feed data into the accounting processes to support hospital administration. In both cases, novel HIS were implemented to address changes within the organizational environment, such as changing regulatory requirements and the pressure to increase the efficiency of patient care (i.e., cost pressure), that could not be appropriately handled by the legacy systems in place.

The implementation strategies and related methodologies adopted in both cases were quite similar. Once a vendor was selected, the general requirements for the HIS were developed. Afterward, the systems were rolled out on a ward-by-ward basis. Both the general implementation strategy and the implementation within the hospital wards followed a standardized waterfall-driven traditional implementation procedure. First, a specification document that reflected ward-specific requirements was created in a joint effort between the project team and key users. The viable requirements were then implemented. Users were trained before the rollout of the HIS in the wards. During the rollout phase, members of the project team were in the wards to help the staff implement the HIS within their dayto-day work and to address emerging incidents.

The software development activities were designed around three key success factors noted in the literature: selection of adequate technology, senior leadership, and 
Table 1 Overview of cases

\begin{tabular}{lll}
\hline Characteristics & CareSys & PatientDoc \\
\hline $\begin{array}{l}\text { Main reason for HIS } \\
\text { implementation }\end{array}$ & Noncompliance with legal requirements & $\begin{array}{l}\text { Reimbursement requires structural data } \\
\text { (productivity constraints) } \\
\text { Legacy tool }\end{array}$ \\
New tool (PDMS) & $\begin{array}{l}\text { 20-year-old legacy PDMS, highly customized and } \\
\text { strongly integrated into operating procedures } \\
\text { Universal PDMS from a major manufacturer, } \\
\text { templates for various medical specialties including } \\
\text { intensive care units; known issues before } \\
\text { implementation were related to usability of recalling } \\
\text { of overviewing data }\end{array}$ & $\begin{array}{l}\text { Specific PDMS for "normal wards" such as } \\
\text { psychiatry and gynecology; known issues before } \\
\text { implementation were cumbersome data entry and } \\
\text { rather weak usability in recalling of overviewing } \\
\text { data }\end{array}$ \\
\hline
\end{tabular}

continuous consultation of key users during all project phases (Cresswell and Sheikh 2013; Cresswell et al. 2013). Thus, we expected that the cases would provide the opportunity to identify peculiarities of healthcare activities not easily recognized by best-practice measures but critical for cushioning contradictions. The following Table 1 gives an overview of the cases, which are presented in more detail below.

\subsubsection{CareSys Implementation Case}

In 2014, the hospital administration decided to replace the legacy PDMS (hitherto CareSysOld). CareSysOld was first implemented approximately 20 years ago and was used in all 15 critical care units of the hospital. Over the years, IT and medical stakeholders made great efforts to align CareSysOld with the existing and emergent characteristics of the activities performed in the critical care units. However, the PDMS no longer complied with Germany's Medical Device Act (implementing EU Directive 93/42/EEC, 2007/47/EC, Article 1, 2a). Further, physicians increasingly asked for advanced medical decision support functions, which were not supported by CareSysOld. Thus, implementing CareSys was primarily aimed at ensuring compliance with new regulatory requirements and improving advanced medical decision support functions.

The high-level requirements that guided the selection of a successor PDMS were primarily developed in alignment with functionalities inscribed in CareSysOld. In developing these requirements, the involved IT professionals were able to draw on their experiences and practical knowledge as former nurses and also integrated the input of selected physicians. Potentially suitable software packages were then evaluated by clinical and administrative users as well as IT professionals.

\subsubsection{PatientDoc Implementation Case}

In 2011, the hospital started an initiative to gradually implement PatientDoc as an additional HIS for care documentation in all nursing-intensive wards, including internal medicine, gynecology, and psychiatry. In total, it was anticipated that PatientDoc would be deployed in 26 general wards to improve compliance with legal requirements (i.e., resolve contradictions between the tools and current regulations), increase the efficiency of day-to-day clinical activities, optimize reimbursement, and so forth. One of the project goals was to develop a standardized core of PatientDoc that would be adapted to the specific requirements of the hospital but identical in all wards. This core was built on templates provided by the vendor and included approximately $80 \%$ of the functionalities needed in all wards. The remaining $20 \%$ were identified as wardspecific and were added as customizations prior to the rollout in each ward.

When we started data collection, PatientDoc had already been implemented in 9 of 26 general wards. Thus, the project team had already gained significant experience in implementing PatientDoc and had defined most of the core functionalities used in all wards. Moreover, the team had gained experience with the various best-practice templates that the vendor provided for various medical specialties and had begun adapting them to ward-specific requirements. For this study, we observed the rollout in the "Addictive Psychiatry" ward.

\subsection{Data Collection}

We collected data for our case CareSys from November 2014 to February 2015 and for our case PatientDoc from November 2015 to March 2016 (see Fig. 2 for details). To ensure the reliability and credibility of the data collected, we applied different methods and involved multiple informants (Miles and Huberman 1994; Walsham 1995, 2006). Specifically, we interviewed key users and project team members and talked to and observed nurses and physicians before, during, and after the rollout of the HIS in the specific wards under study. Please note that we did not observe the rollout of the HIS in all wards of the hospital. In addition to interviews, we reviewed project- 
Table 2 Formal interviews

\begin{tabular}{lll}
\hline Interviewee & Interviews (length) & Documentation \\
\hline CareSys & & \\
CS-PT01 (Project manager, IT consultant, external) & $1(70 \mathrm{~min})$ & Notes/report from memory \\
CS-PT02 (Project team, IT staff, nursing background) & $1(120 \mathrm{~min})$ & Notes/report from memory \\
CS-PT03 (Project team, IT staff, nursing background) & $2(105 \mathrm{~min})$ & Verbatim report \\
CS-SH01 (IT manager, medical background) & $2(70 \mathrm{~min})$ & Notes/report from memory \\
CS-NU01 (Nursing manager) & $3(120 \mathrm{~min})$ & Verbatim report \\
CS-NU02 (Nurse on the ward) & $1(30 \mathrm{~min})$ & Verbatim report \\
CS-NU03 (Nurse at the ward) & $1(60 \mathrm{~min})$ & Verbatim report \\
CS-PH01 (Assistant medical director) & $1(40 \mathrm{~min})$ & Verbatim report \\
CS-PH02 (Assistant medical director) & $1(65 \mathrm{~min})$ & Verbatim report \\
CS-PH03 (Physician in the ward) & $1(40 \mathrm{~min})$ & Verbatim report \\
PatientDoc & & \\
PD-PT01 (Project manager, IT professional) & $1(45 \mathrm{~min})$ & Notes/report from memory \\
PD-PT02 (Project team, IT professional) & $3(90 \mathrm{~min})$ & Notes/report from memory \\
PD-PT03 (Project team, nursing background) & $1(40 \mathrm{~min})$ & Verbatim report \\
PD-PT04 (Project team, nursing background) & $1(50 \mathrm{~min})$ & Notes/report from memory \\
PD-PT05 (Project team, nursing background) & $1(50 \mathrm{~min})$ & Notes/report from memory \\
PD-NU01 (Nurse in the ward) & $3(110 \mathrm{~min})$ & Verbatim report \\
PD-NU02 (Nurse in the ward) & $3(70 \mathrm{~min})$ & Verbatim report, notes \\
PD-M01 (Ward manager, nursing line manager) & $3(100 \mathrm{~min})$ & Verbatim report, notes \\
\hline
\end{tabular}

related documents such as requirements specifications and training material. Data on the implementation of CareSys was collected in two intensive care units, while data on the implementation of PatientDoc was collected in a single ward of the psychiatric clinic. The teams of both projects had significant experience, as both HIS had already been rolled out in other wards within the hospital. Moreover, the templates of the HIS were already refined so that they sufficiently covered most standard requirements during these prior rollouts.

The formal interviews were set up as semi-structured conversations supported by an interview guideline (Yin 2009). The guideline concerning the PatientDoc implementation primarily focused on the interviewees' knowledge and experiences regarding the affected activities and the role of the HIS. The guideline used for the CareSys project also contained open questions on the nature and quality of interactions between the various occupational groups involved (e.g., IT professionals, physicians, and nurses).

Table 2 summarizes the interviews conducted in each case study.

The purpose of holding interviews was to understand knowledge-integration processes between the project team and the users and, in particular, to determine what knowledge, experiences, and perspectives they shared. The interviews were recorded and transcribed whenever possible. For the interviewees who did not want to be recorded, we took comprehensive notes and prepared a report from memory based on these notes immediately after the interviews.

To identify emerging incidents and to collect data pointing to contradictions within the activity system potentially capable of causing critical incidents, we also observed how users interacted with the HIS either during or shortly after the rollout. Therefore, we spent several days in the wards and observed how the physicians and nurses interacted with both the legacy tools and the HIS. In addition, we conducted numerous informal conversations with nurses, physicians, and the members of the project team to gain an understanding of the critical incidents we observed and to identify underlying contradictions in the activity systems. These casual conversations and observations were immediately recorded in the case diary.

\subsection{Data Analysis}

For analyzing the data, we followed the guidelines of Miles and Huberman (1994). To ensure interrater reliability, one researcher coded the data and a different researcher crosschecked the coding. Different views on the coding were discussed and resolved within the team. Once agreement on the coding was reached, the team compared, analyzed, interpreted, and discussed emerging patterns concerning the characteristics of the activity systems (Miles and Huberman 1994). Whenever the interpretations differed, the research team went back to the data, theory, and/or the field and discussed the findings until an interpretation was 


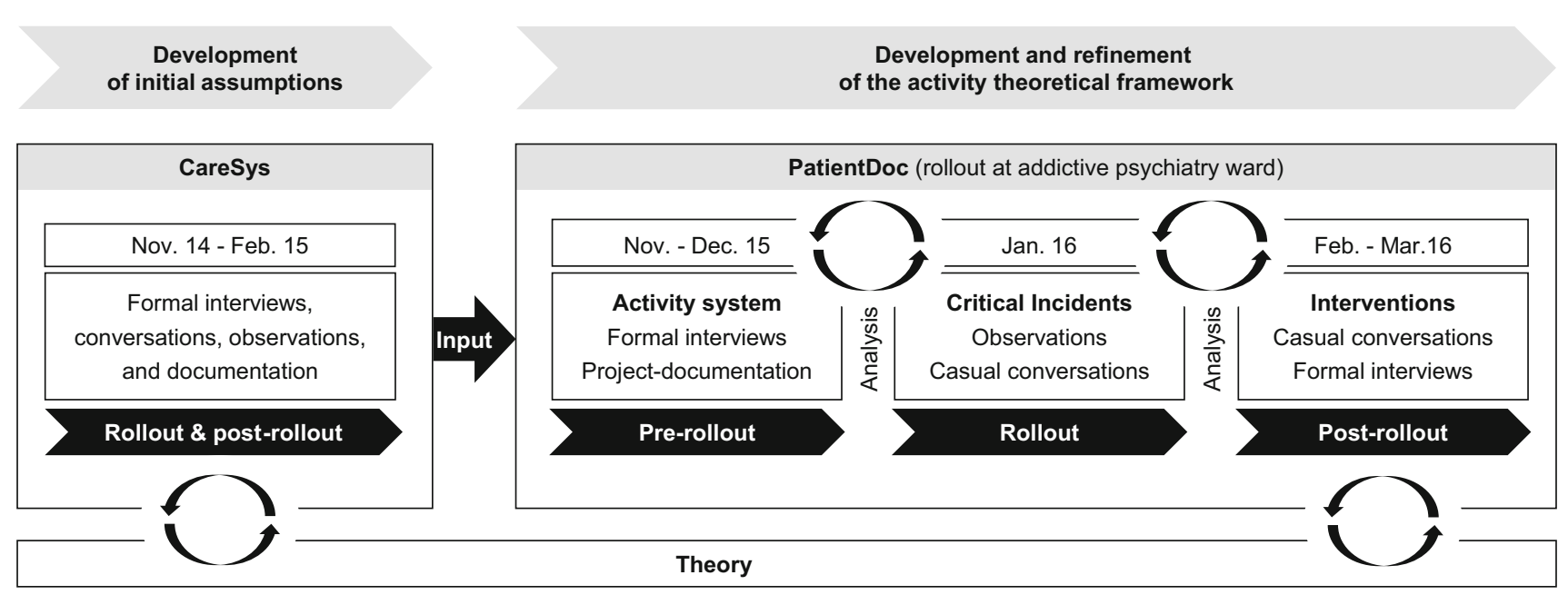

Fig. 2 Iterative process of data collection and analysis

developed that was plausible for all authors (Walsham 1995).

Figure 2 shows the timeline of the data collection and analysis for our two sequential cases. We started with CareSys and followed up with PatientDoc. As visualized in Fig. 2, we first analyzed the CareSys data. Based on the theoretical and empirical insights gained (denoted as an arrow labeled "Input" in Fig. 2), we then planned and conducted data collection and analysis for the second case study. As discussed, the second study was conducted to increase the robustness of the findings. Thus, we looked for similar or contrasting episodes and compared the characteristics of the activity systems and the observable results (i.e., post-implementation success). To increase our understanding of the activity system before implementing PatientDoc, we chose to extend data collection to the prerollout phase in the second case (see Fig. 2).

As depicted in Fig. 2, our understanding of the contradictions, their origins in the activity system and type (latent, salient), and the interventions geared to address them was continuously informed and shaped by a continuous interplay between data collection, analysis and consideration of theory (Walsham 2006). Going back and forth from the field to data and theory lasted until the research team had a common understanding of the characteristics of the activity systems before and after implementation.

The iterative data analysis process was as follows: First, data on the individual conceptions of the work activity was coded following an open coding approach (Miles and Huberman 1994). Second, the resulting codes were analyzed, and subordinate categories were formed. These categories were then assigned to an element of the activity system (e.g., subject or rule) or a relationship between multiple elements (e.g., relationship between actors and implicit rules). Third, we compared the findings in each category to identify similarities, connections, and patterns between the individual conceptions. Fourth, we analyzed the post-implementation issues that emerged during the rollout and tried to identify which contradictions between elements of the activity system might cause them. To do this, we coded data from the rollout phase in search of characteristics of the activity system that had not previously been shared as well as indications of underlying contradictions (either latent or salient). We again created categorical codes, compared the resulting codes with the activity system elements, and assigned them to one of the activity system codes. Finally, we analyzed the coded data and created a conceptual matrix (Miles and Huberman 1994). For each incident we observed, the matrix encompassed the characteristics of the activity system before and after the changes or management interventions. Thus, the matrix allowed us to generate an overview of relevant data and synthesize case study data into illustrations of contradictions and related interventions, as reported in this study. Moreover, we used the conceptual matrix to analyze how the post-implementation issues reported in the case illustrations related to perspectives, knowledge, and experience that were evidently not shared during the adaptation and implementation of the PDMS. This iterative process resulted in our activity theoretical model. Finally, we returned to the data from our first case study (CareSys implementation) and reanalyzed whether this framework offered a conclusive interpretation of the outcome of this case.

\section{Findings}

In both cases, the HIS were adapted and implemented in a way that enabled relevant actors to document patient data, 
comply with regulatory requirements, and ensure higherquality data for the purpose of overcoming productivity constraints, particularly concerning reimbursement. However, we identified contradictions within the activity systems manifesting as post-implementation issues that led to significant inefficiencies. Some of the management interventions observed were effective in mitigating the contradictions, while others were not.

For both cases, we first report on the legacy tool and then move on to report on the implementation of the new HIS. We flesh out the characteristics of the activity systems and post-implementation issues observed and relate them to the contradictions that changed from latent to salient after implementation or contradictions that emerged only post-implementation in the activity systems. Both contradictions are marked with italics. Finally, we report the management interventions applied and offer our analysis of whether and why they were effective.

\subsection{CareSys}

\subsubsection{Salient Contradictions Before HIS Implementation}

We found CareSysOld to be well-aligned with other elements of the activity system within the wards observed, i.e., the critical care units. This is not surprising because CareSysOld was constantly adapted over the years to fit the specifics of the activity systems in different wards. However, CareSysOld was not compliant with regulatory requirements induced by the organizational environment (Medical Device Act, hereafter MDA). Thus, we identified a contradiction between the activity system elements of tools (CareSysOld) and rules (regulatory requirements). Furthermore, the system was highly customized and difficult to stably operate and did not provide the increasingly demanded enhanced decision support capabilities for physicians, which we identified as a contradiction between the activity system elements of tools and subjects. This contradiction was also caused by the limited range of patient and treatment data that could be recorded in a structured way with CareSysOld.

\subsubsection{Latent Contradictions Before HIS Implementation}

Looking at the rules and the division of labor that govern patient treatment in the ward, we found some noteworthy characteristics. Firstly, from a legal perspective, physicians have almost sole decision-making authority, while the nursing staff is responsible for doing the "groundwork" (e.g., collecting data) and executing care-related treatment decisions (e.g., administering drugs). Moreover, we observed that the interactions between the actors are shaped by definitive roles and task assignments within and between different professional roles. This was, for instance, observable during the case discussion sessions. Here each patient's health status, current treatment, and medical history - the cases - were discussed based on the data recorded in CareSysOld. Using CareSysOld, the responsible physician could quickly outline the treatment plan and the patient's health status and the nurses could report their activities. The chief physician would then ask questions and decide on adaptations to the treatment plan. Each single patient case was reviewed very quickly. Once the case discussions were finished, the nursing staff was required to execute the decisions, document their activities, and collect further data to be discussed during the next session. Nurses were responsible for documenting and updating the treatment plan and administering all prescriptions, documenting their own activity, and documenting the patient's health status. These tasks require a considerable amount of time, during which nurses were unavailable to care for patients. Here, we found a latent contradiction between the subjects, division of labor, and object that did not surface because CareSysOld provided sufficient flexibility to reorganize the task distribution and to assign documentation tasks to volunteers or trainees. This, in turn, allowed subjects to allocate more time to the object - namely, patient health status. In that regard, CareSysOld was found to be an integral part of this and other parts of the activity system in that it facilitated coordination between the different medical specialties, was wellaligned with the requirements of the various professional roles and specialties, and reflected the culture in the wards (e.g., "command and control" during case discussions). However, during our interviews we observed a contradiction between how physicians and nurses view patient health status as the object of their common work activity: while physicians want to learn as much as possible about patients and expect nurses to collect most of this data (i.e., change of vital data), nurses want to care for the patient as directly as possible. That is, there is a contradiction between the activity system elements of subject and object in that different subjects (physicians and nurses) have contradictory motives toward the object of the activity system. This contradiction was latent, as it had no observable dysfunctional effect on the activity. This contradiction was masked by CareSysOld, which was efficient for nurses to use because it, for example, allowed the use of shortcuts for data entry. CareSysOld did not force nurses to enter all the detailed data desired by physicians, thus allowing them to report only data that was meaningful from their perspective, leaving more time for patient care. 


\subsubsection{Effects of HIS Implementation}

As designed, the new HIS (CareSys) explicitly considered the regulatory changes and the demand for enhanced decision support capabilities for physicians. Consequently, the two contradictions found with the old HIS (CareSysOld) between the activity system elements of tools and rules (regulatory requirements, salient) and between tools and subjects (physicians requiring enhanced decision support capabilities, latent) were resolved through changes in the activity system element of tools realized through the implementation of a new HIS. However, once CareSys was rolled out, a new contradiction between the activity system elements of subject, rules, and object appeared through explicit rules governing the coordination of subjects in terms of the object. These rules are characterized by "command and control," whereby physicians decide, and nurses execute; since these rules were encoded in CareSys, they did not allow for exceptions and workarounds as did the old system.

Furthermore, the already mentioned latent contradiction between the activity system elements of subject and object, where different subjects (physicians and nurses) had contradictory motives toward the object of the activity system, surfaced and became salient because the new system required all the detailed data that physicians wanted and did not allow for short-cuts. Therefore, while physicians got the information they demanded ("most things are available," CS-PH3), nurses had to devote much more effort to documentation ("it may fulfill the needs of "Mr. Professor', but not those of a nurse," CS-NU03). Mostly due to ensuring conformity with the MDA, CareSys was less adapted to the historically evolved processes and the specifics of the different wards. In addition, while CareSys offers the ability to record a much wider range of data, since not all data is relevant for all medical specialties, this can lead to crowded interfaces ("too big, too confused, too complex, too much", CS-NU01). Because they were tasked with recording all data "demanded" by CareSys, nurses' documentation efforts significantly increased, thus reducing the time available for direct patient care ("We are facing additional work time of up to a half hour per patient," CS-NU01 and CS-NU02). The relatively strict "command and control" culture in the wards that was now encoded in CareSys made the situation even worse: the nurses did not question whether they had to collect all data for every patient. Rather, they tried to provide all the data CareSys requested, even though not all fields are relevant for all patients in all wards. This, in turn, surfaced the latent contradiction that, while present with the old HIS, did not previously manifest as a problem or a breakdown. Overall, the nurses were deeply disappointed when CareSysOld was replaced by CareSys, particularly because they had less time to do what motivates them - take care of patients.

However, the nurses were not the only actors who were upset. Although CareSys offered the requested enhanced diagnostic features, physicians also had difficulties letting go of the procedures that had been in place for decades. In the case review setting, for instance, CareSys did not enable physicians and nursing staff to quickly recall patient and treatment status and - even more importantly - did not allow them to answer the chief physician's questions nearly as quickly as before ("I am clicking myself to death," CSNU01). The amount of data available in CareSys and the specifics of the user interface made it difficult to get an overview of the data quickly and to fulfill traditional roles during case reviews. As with other observed incidents, it was only during the rollout that the project participants determined that although CareSys fulfills the requirements of the MDA, it is not flexible enough to adapt to the traditional structures in the wards that had shaped the activity system for years. These traditional structures involved, for example, assigning documentation and data retrieval tasks to trainees or volunteers to cope with requirements of data collection and retrieval, thus freeing up capacity for physicians and nurses, who could in turn allocate more time to the object. The new HIS hardwired a specific distribution of tasks; consequently, the traditional distribution of work and responsibilities among physicians, nurses, and other actors, such as trainees or volunteers, no longer worked. Accordingly, the previously mentioned latent contradiction between subjects, division of labor, and object became salient, as the new HIS implied a change in the division of labor. However, since nurses did not agree with the change, this caused disturbances between subjects and the object because treatment could no longer be efficiently provided.

Overall, implementing the new HIS - CareSys - significantly disrupted patient treatment activities and noticeably reduced efficiency. Both physicians and nurses perceived CareSys as "too overloaded" (CS-NU3), "complex" (CS-PH3), and "inflated" (CS-PH1). Overall, the issues led nurses to demand a rollback of CareSys and to resist using CareSys if it did not jeopardize patient safety. Management interventions after the rollout, as well as unintended balancing mechanisms that led to adaptions of complementary elements of the activity system, mitigated the contradictions and reduced negative effects. For instance, each ward announced explicit instructions regarding the specific data that needed to be collected. This intervention led to reduced documentation efforts so that nurses could once again focus more on direct patient care. In addition, physicians and nurses began to maintain an additional paper-based summary of the most important information for case reviews. 


\subsection{PatientDoc}

\subsubsection{Salient Contradictions Before HIS Implementation}

In contrast to the CareSys implementation, where a predecessor information system existed (see Sect. 4.1), in the wards under study in the PatientDoc case, predominantly paper-based tools were used to document and review patient data. On the one hand, these paper-based tools limited the possibilities of physicians, as the scope of structured documented data was restricted and it was not possible to apply extended diagnostic functions based on the available data. Moreover, because of the restricted scope of structured documented data, the paper-based documentation impeded management efforts to invoice medical services comprehensively and efficiently with insurance companies and other payers. Thus, there were clear contradictions between subjects and tools, as the paper-based tools did not for allow extended diagnostic functions and efficient reimbursement. Looking at the exchange value of the activity, important managerial aspects of patient treatment could not efficiently be performed, particularly in terms of complete and comprehensible reimbursement requests.

\subsubsection{Latent Contradictions Prior to HIS Implementation}

The paper-based documentation tools were found to be well aligned with complementary elements of the activity system and they successfully balanced the, to some extent, opposing requirements of physicians and nursing staff for a long time. Here, as in the CareSys case, we identified a latent contradiction between the activity system elements of subject and object rooted in the different motives of the subject groups (physicians and nurses) toward the object of the activity system. Physicians demanded more information for diagnostic purposes, requiring nurses to devote more effort to collecting and documenting, which reduced the amount of time available to nurses for patient care. Also, as we will see below, the paper-based documentation tools provided enough flexibility to enable physicians and nurses to deal with the ever-increasing workload in the wards (induced by the organizational environment) and allowed them to make most of their specific competencies and experiences. For instance, although the physicians and nurses working in the Addictive Disorders ward had developed an effective medication management procedure over time (local, ward-specific, implicit rule), this approach may not have been fully compatible with legal requirements: by law, nurses are only allowed to administer drugs as prescribed by a physician. However, since physicians are not always physically present in the ward, this sometimes created problems; in certain situations (e.g., emergencies), nurses needed to adapt the dosage intervals themselves and then get authorization by phone (e.g., in cases of acute delirium, restlessness, or shivering). Moreover, we found that physicians were not always entirely comfortable in setting the dosages without consulting a nurse. They even asked whether it "is possible to calculate the optimal dosage within the system" (observation note). Therefore, following implicit, ward-specific rules enabled the involved actors to effectively care for their patients. Moreover, the flexibility offered by the paper-based tools enabled the physicians and nurses to ensure that they avoided legal problems. A similar example relates to trainees and volunteers. In some wards, the way that tasks were distributed was continuously adapted in order to cope with increasing cost pressures and workload. Volunteers and trainees were increasingly asked to measure and document vital parameters. Though supervision by a certified nurse and authorization of the documentation is legally required, volunteers and trainees frequently performed these actions on their own. This saved valuable nursing time, which could then be allocated to direct patient care. In that regard, like in our other case, CareSys, we identified a latent contradiction between the activity system elements of subject, division of labor, and object that did not surface because of the flexibility of the paper-based tools. Physicians and nurses (subjects) developed an efficient task distribution (division of labor) which, for example, "allowed" for medication prescribing by experienced nurses and documentation by volunteers. This freed up physicians' and nurses' capacity, allowing them to devote more time to patient care, thus supporting patient health status (object). Overall, the paper-based documentation tools were able to balance divergent needs, cushioned contradictions, and prevented problems and breakdowns within the activity system; thus, the latent contradictions did not surface in the old system.

\subsubsection{Effects of HIS Implementation}

The new HIS resolved the contradiction between subjects and tools regarding the limited ability of the paper-based tools by fulfilling and physician requests for extended diagnostic functions and management requests for improving the reimbursement through providing the respective functionality to collect and analyze data in a structured manner. The new HIS, thus, provided a synergistic solution for humanistic goals related to physicians' ability to diagnose and instrumental goals related to management's ability to implement efficient reimbursement requests. However, although the HIS implementation made detailed, structured information more quickly available for reimbursement purposes, replacing the legacy tools with PatientDoc caused the abovementioned latent 
contradiction between subjects, division of labor, and object within the activity system to become salient, which jeopardized implementation success.

First, PatientDoc rendered existing modes of task distribution impossible. Although it was previously known that, in compliance with IT policy, volunteers did not possess user accounts authorized to perform documentation in PatientDoc, this only became problematic after the rollout, because only nurses and trainees were able to document vital parameters. Thus, the evolved division of labor was no longer applicable and the efforts that nurses were required to devote to documentation increased considerably. Nurses now had to spend more time recording vital parameters on their own or accompanying volunteers and trainees. PD-NU01, for instance, stated that nurses now "spend too much time at the computer and have less time for the patients"; also, many nurses did not want to key in data they did not collect ("I will not key in data that I have not measured,” PD-NU03).

Second, neither physicians nor nurses were able (or willing) to anticipate that PatientDoc would considerably restrict the flexibility of medication management, particularly in cases of emergency. During the rollout of PatientDoc, however, nurses recognized that PatientDoc records the time and date that medication dosages are adapted and administered and does not allow them to adapt the administration of medications on short notice or to enter physicians' authorization after administering adapted medication. Understanding these limitations affected their attitudes toward PatientDoc significantly, causing some of them to even resist using PatientDoc until it was clarified how medication management in cases of emergency would be governed and how conflicts would be resolved. Like the abovementioned contradiction that was present but latent in the old system and became salient only after HIS implementation, the latent contradiction between the subjects and object of the activity became salient through the HIS implementation.

As discussed above, we identified different motives of the subjects (physicians and nurses) toward the object of the activity system. Physicians demanded more information for diagnosis purposes to better fulfill their objectrelated tasks and nurses wanted more time to care for patients in order to better fulfill their object-related tasks improving patient health status in both cases. However, since more information for diagnostic purposes requires data collection and documentation to be carried out predominantly by nurses, there seemed to be a trade-off that had been balanced prior to the implementation of PatientDoc. For example, the nurses in the Addictive Disorders ward created and gradually refined "monitoring sheets" for every patient. These sheets hung on the blackboard and helped nurses to keep track of patients (e.g., in case of emergency and during shift handovers) and provide optimal care to patients. Vital parameters, adapted dosages, and other important events were recorded on these sheets before the formal documentation was updated. For nurses, this was an efficient way to perform documentation tasks.

During requirements elicitation for the new HIS, it was decided that the monitoring sheets should be replaced with PatientDoc reports because recording and analyzing data directly in PatientDoc would reduce errors and provide physicians with instant access to care documentation. While PatientDoc was able to satisfy the information needs of physicians, the reports offered by the software were not able to replace the monitoring sheets sufficiently. For instance, PD-NU02 stated that "the monitoring sheets enabled us to get an overview on patients much more easily ... which is quite important in a closed psychiatric ward." Commonly cited reasons for the contradiction were that the reports had to be activated manually, were only accessible via the small monitors in the wards, and did not give nurses a quick overview of the patients and their care needs. In addition, the new reports were optimized for physicians and thus included more detailed data than before, which had to be collected and documented by nurses. Furthermore, PatientDoc made shift handover considerably more cumbersome, ultimately resulting in the nursing staff continuing to maintain and use the legacy tool.

Thus, this now salient contradiction between the activity system elements of subject and object was rooted in the different motives of the subjects (physicians and nurses) toward the object of the activity system. Physicians demanded more information, which led to replacing the monitoring sheets, which, however, did not fulfill the information needs of nurses because it made it more difficult to get a quick overview of the object. In addition, time devoted to taking care of patients was reduced by inefficient shift handover.

In order to reduce these unintended effects, management interventions to adjust the structure of the activity system were necessary. To ensure compliance with legal regulations, management implemented extended planning periods and IS-supported identification of appropriate medication schemes for critical drugs to prevent short-term adjustments. In addition, management directed physicians and nurses to document medication adjustments before administration, even if no physician was on site. To smooth these operations, physicians were trained to document adaptations remotely. Likewise, management gave trainees and volunteers permission to use the accounts of trained nurses to record vital parameters, explicitly legitimizing this practice, even though went against IT policy regulations. Moreover, although management discontinued the use of the monitoring sheets, they installed large screens in 
the ward rooms for displaying patient reports and provided notebooks to ease ward rounds and shift handovers.

\section{Summary of Findings}

Both HIS implementation projects sought to address contradictions such as noncompliance with regulatory requirements and increasing economic pressures. However, as with similar HIS implementation initiatives reported in prior literature (Cresswell and Sheikh 2013), adapting the tools of the activity systems led to unanticipated contradictions, even though project management design was based on experiences from several prior rollouts as well as on best-practices and templates.

As shown in the analysis of the cases, most post-implementation issues observed can be traced back to unapparent characteristics of the activity system and how they related to adaptations of the tools. Although project management enabled subjects to identify key stakeholders, their individual expectations, obvious properties of the legacy tools related to individual tasks, and important regulatory needs, it was not able to fully capture the effects of the intended changes. In particular, less obvious elements and characteristics of the inherent structure of the activity system such as latent contradictions that were covered by the mediating role of the legacy tools affected the functionality of the activity system. The resulting post-implementation issues were identified as engines for management interventions aiming to solve or mitigate contradictions. Table 3 summarizes these contradictory, tool-mediated relationships between elements of the activity systems. Contradictions that had been resolved through implementing new HIS are reported in Sects. 4.1 and 4.2 but are not included in the table. The first column of Table 3 identifies tool-mediated relationships between elements where we identified contradictions. The second column describes the contradiction and presents the probable cause of the contradiction. We observed that these contradictions and their causes are similar in both cases and could detect no major differences. The third column of Table 3 highlights the interventions undertaken to counter the contradictions (details on the interventions are discussed in Table 4). These interventions are all designed as changes to specific elements of the activity system and encompass changes to at least two elements simultaneously. In contrast to the contradictions, our cases differ in terms of interventions taken.

Although the specific interventions taken in the cases differ, the interventions led to a realignment of similar contradictory, tool-mediated relationships within the activity systems. Ultimately, the interventions facilitated stabilization of the activity system. In particular, the re- stabilization of the activity system was demonstrated by the decreased resistance to it: the HIS was increasingly integrated into daily routines and the overall efficiency of inpatient healthcare increased. Ultimately, our analysis shows that the combination of the interventions and the resulting mitigation of the contradictions prevented the implementation projects from failing.

Table 4 shows which management interventions were undertaken in response to the observed post-implementation issues and how they contributed to the mitigation of the underlying contradictions (whether latent or salient). As depicted in the first column of Table 4, we did not observe any interventions that aimed to adapt more than one element of the activity system to mitigate or post-implementation issue to solve. Given the contradictory relationships between multiple elements that caused post-implementation issues, multiple interventions were needed to mitigate the contradictions within the activity system and enable stabilization. However, since the focus of this study was not to better understand the interrelations between interventions, our data does not offer enough evidence to further analyze the interdependency of the interventions.

\section{Discussion}

In this section, we first discuss the nature and causes of the three types of tool-related contradictions evolved in our analysis in more depth and, subsequently, derive implications for theory and practice.

\subsection{Nature and Causes of HIS-Related Contradictions}

The first type of HIS-related contradiction identified in this study is the contradiction between subject and object. This contradiction is latent in nature and may be mitigated or reinforced by the introduction of a new tool, i.e., the HIS. It reflects that healthcare activities are inherently characterized by contrasting perspectives on the object of the activity system among different groups of subjects and related motives (Klauber et al. 2010; Fichman et al. 2011), i.e., patient health status. One motive derives from the desire to devote as much time as possible to patient care, while another motive is based on the need for sufficient data to make an accurate diagnosis. The motives are interrelated in that they both seek to improve patient health status. However, the motives are also contrasting because accurate diagnosis requires collecting and documenting as much data as possible, which, in turn, takes time away from nurses seeking to devote maximum time to patient care (the other motive). As the new HIS leads to an amplification of the inherent contradiction, i.e., the HIS made a latent contradiction salient, it can be concluded that 
Table 3 Characteristics of the activity system related to contradictions

Contradictory, tool- Contradictions in the activity system after implementation Management interventions to counter contradictions mediated relationship

Subject-Object

(latent $\rightarrow$ salient)

Subject-Rules-

Object (new salient)

Subject-Division of

Labor-Object

(latent $\rightarrow$ salient)
This contradiction was latent prior to the implementation and became salient through the new IS. The adapted toolset reveals that physicians and nurses (the subjects) exhibit contradictory motives towards the object of the activity system and overemphasizes the objectives of physicians

Physicians demand a lot of data per patient (e.g., for informed decision making and research); nurses must collect most of this data. The PDMS forced nurses to collect more data, which limits the time available for caring for patients (their motive). Moreover, the PDMS did not ease their work, e.g. the reports could not replace the legacy tools such as monitoring sheets

Ultimately, the PDMS increased conflicts between the medical specialties of nurses and physicians concerning their contradictory perspective of the object and related motive. This fostered resistance among nurses and consequently jeopardized the activity system's outcome, as they saw their interest in having time for patients at risk

This contradiction newly appeared after the implementation of the new PDMS

Explicit rules that govern the coordination of healthcare actors (the subjects, namely nurses and physicians) toward patient health status (the object) follow a "command and control" scheme, where higher-ranked individuals (physicians) decide and subordinates (nurses) execute. The new PDMS encodes these rules and allows fewer exceptions (e.g., for drug prescription and administration) compared to the more flexible paperbased legacy tools, even in emergency situations

Ultimately, the PDMS limited the historically evolved autonomy of nursing staff and rendered it difficult to provide faster patient care, particularly in emergency situations

This contradiction was latent prior to the implementation of the new PDMS and became salient through the new PDMS. The new PDMS affects established forms of task distribution and impedes efficient patient care

To cope with increasing workload, efficient modes of task distribution (division of labor) have been developed over time (e.g., shift handover procedures and documentation of vital parameters by volunteers and trainees) to be efficient and effective towards the object (patient health status)

The PDMS made this type of task distribution impossible initially (features, authorization)
Adaptions to the PDMS:

Adaption of reports and patient data templates and installation of large screens for displaying patient reports / patient overview reports to better meet nurses' needs

Deployment of mobile devices to ease data entry

Adaptions to subjects:

User training to use the PDMS more efficiently

Increasing awareness of nurses concerning the necessity of recording data digitally

Adaptions to local, ward- specific rules:

Revision of documentation rules (e.g., specification of data to be collected, documentation in before administration)

Alignment of evolved local rules with legal requirements that are inscribed in the PDMS

Adaptation of local medication rules (extended planning periods to avoid short-term adjustments; only in PatientDoc case)

Adaptions to subjects:

Training of physicians to prescribe drugs remotely

Adaptions to local, ward-specific division of labor:

Trainees and volunteers were explicitly allowed to use the accounts of trained nurses

Adaptions to the PDMS:

Deployment of mobile devices to ease ward round and shift handovers the legacy tools and the new tool emphasize perspectives on the objects and related motives differently. More specifically, implementing HIS bears the risk that it does not sufficiently account for divergent motives among the subjects of the activity system, e.g., as it creates more or less autonomous practices within different groups of subjects geared toward the respective motives, which leads to incompatible arrangements (compare Seo and Creed 2002).
These arrangements did not materialized in the old system because the legacy tool allowed for sufficient flexibility.

The different perspectives of the subjects on the object and related motives are rooted in humanistic goals (Sarker et al. 2019). In our case, the humanistic goal of physicians and nurses was almost identical and focused on patient health status. However, the related motives (ensuring better data for diagnoses; securing sufficient time for patient care) 
Table 4 Major management interventions and their effects

\begin{tabular}{|c|c|c|c|}
\hline \multirow{2}{*}{$\begin{array}{l}\text { Addressed } \\
\text { element of the } \\
\text { activity } \\
\text { system }\end{array}$} & \multirow{2}{*}{$\begin{array}{l}\text { Interventions to counter } \\
\text { or mitigate } \\
\text { contradictions }\end{array}$} & \multicolumn{2}{|l|}{ Case observations } \\
\hline & & CareSys & PatientDoc \\
\hline \multirow[t]{2}{*}{ Subject } & $\begin{array}{l}\text { Additional/adapted user } \\
\text { training }\end{array}$ & $\begin{array}{l}\text { Additional user trainings } \rightarrow \text { helped increase } \\
\text { efficiency in using the PDMS }\end{array}$ & $\begin{array}{l}\text { Key-user training } \rightarrow \text { helped to improve } \\
\text { efficiency, particularly among nurses }\end{array}$ \\
\hline & $\begin{array}{l}\text { Discussing/ } \\
\text { communicating } \\
\text { perspectives of } \\
\text { specialties/specific } \\
\text { necessities }\end{array}$ & $\begin{array}{l}\text { Discussions in cross-specialty user } \\
\text { groups } \rightarrow \text { facilitated understanding of differing } \\
\text { perspectives; led, among other things, to a } \\
\text { mutual agreement concerning the amount of data } \\
\text { that needed to be documented }\end{array}$ & - \\
\hline Tools & $\begin{array}{l}\text { Feature-alignment to } \\
\text { specialty-specific/local } \\
\text { needs }\end{array}$ & $\begin{array}{l}\text { Adaptions to PDMS } \rightarrow \text { improved usability and } \\
\text { effort reduction }\end{array}$ & $\begin{array}{l}\text { Adaptions to PDMS (reports and entry forms); } \\
\text { deployment of additional devices } \rightarrow \text { improved } \\
\text { usability and effort reduction; improved } \\
\text { response times in case reviews }\end{array}$ \\
\hline Rules & $\begin{array}{l}\text { Alignment of ward- } \\
\text { specific directions with } \\
\text { codified rules }\end{array}$ & $\begin{array}{l}\text { Installation of documentation rules for } \\
\text { PDMS } \rightarrow \text { reduced documentation effort and } \\
\text { tolerance of a paper-based summary for case } \\
\text { reviews }\end{array}$ & $\begin{array}{l}\text { Adaption of local medication rules } \rightarrow \text { reduction } \\
\text { short-term adjustments and alignment with the } \\
\text { procedures inscribed in the PDMS } \rightarrow \text { reduced } \\
\text { autonomy of the nurses }\end{array}$ \\
\hline $\begin{array}{l}\text { Division of } \\
\text { labor }\end{array}$ & $\begin{array}{l}\text { Adaptions to evolved } \\
\text { modes of task } \\
\text { distribution }\end{array}$ & - & $\begin{array}{l}\text { Realignment of task-distribution including } \\
\text { official policy } \rightarrow \text { nurses could once again } \\
\text { handle their workloads }\end{array}$ \\
\hline
\end{tabular}

and, consequently, the ways of achieving this goal differed among subjects. Regarding these motives, we argue that it is not about an "either-or" but a "both-and" situation. The two motives and the means of achieving the goal are both relevant and necessary and simultaneously point to the importance of finding synergistic solutions. In that regard, we also found that several complementary tool-related interventions, such as the adaption of reports and patient data templates, installation of large screens for displaying patient reports, and the deployment of notebooks to facilitate ward rounds, were needed to mitigate the contradiction.

The second type is a new contradiction, which is originally induced by the HIS and located in the tool-mediated relationships between subjects, rules, and the object. Understanding this salient contradiction, requires consideration of healthcare as a context that is highly influenced by explicit regulation and traditional hierarchies (Fichman et al. 2011), in which exceptions are nevertheless regularly called for, especially in case of emergency. In addition, there are rather implicit coordination rules between different groups of subjects in place - in this case, "command and control" rules, where physicians make decisions and nurses execute. Since HIS are often designed to comply with standards, formal rules, and hierarchies, they have the potential to intensify contradictions between formal rules and implicit conventions, or to create new ones, and new contradictions may be caused by the conflict between efficiency demands and the need to conform with institutional arrangements such as traditional hierarchies (Weeger and Gewald 2015). As compared to the legacy tool, a newly implemented HIS may reduce flexibility, thus impeding the autonomy of some actors and reducing the ability to govern local and temporal variations. If this is the case, the relationships between the tool and implicit and explicit local rules need to be re-aligned.

The third type of contradiction is a latent contradiction within the tool-mediated "subject-division of labor-object triad" that is reinforced by HIS implementation. Patient care and, thus, the object of the activity system, i.e., patient health status, involve an inherent contradiction between the need for stability and the need for flexibility to allow for variation (Fichman et al. 2011). The division of labor (e.g., task distribution between nurses, trainees, and volunteers) evolved and/or was negotiated over time to support orderly routines and to account for local or temporary variations by, for example, assigning tasks to trainees or volunteers to allow nurses to spend more time caring for patients. A new tool may impose another division of labor through enforcing authorization concepts that restricted access to functionalities for certain user groups. Consequently, workarounds like assigning tasks to trainees in order to free up time for patient care could be no longer possible, which in turn makes the latent contradiction salient. This latent contradiction is rooted in the conflict between conformity with institutional arrangements (compliance rules related to which tasks are assigned to which groups of subjects) and efficiency demands (offloading tasks to free up time). It 
may become salient because the dominant group imposed its needs and ideas onto the HIS implementation, resulting in a conflict with the efficiency demands of other groups (Seo and Creed 2002).

The following Table 5 summarizes the tool-related contradictions found, and recommendations derived.

\subsection{Implications for Theory}

The findings of this study provide further evidence that increases the understanding of IT as an inherent component of human activity for both academia and practice. The conception of IT as an interlinked and mediating artifact within complex activity systems comprising other tools, rules/norms, and the division of labor is in line with the conception of IT as an artifact that is interwoven with other object-related entities.

This study extends research on post-IS-implementation issues associated with misalignments between different groups of users and the IS that investigates use, misuse, or nonuse by these user groups (e.g., Boudreau and Robey 2005; Berente et al. 2016; Oborn et al. 2011) by clarifying the relationship between post-implementation issues and contradictions in the network of interactions between an HIS and various elements of the healthcare context and by evaluating the effectiveness of countermeasures. While previous studies deliver valuable insights regarding the causes of post-implementation issues, they mostly focus on issues between IS and user practices, even though research indicates that inscribed social structures such as the division of labor may invoke issues beyond those observed as occurring between IS and user practices (Allen et al. 2013b; Karanasios and Allen 2013). By using the concept of activity systems to account for various social and technical elements, including but not restricted to IS and users, we offer the following contributions to theory.

\subsubsection{Contradictions as Conceptual Tool to Identify Post- implementation Issues}

Drawing on AT, we specify misalignments as contradictions between elements of the activity system. Per se, contradictions are inherent in all human activities, as they are rooted in a given primary contradiction between the use value (i.e., the needs an activity fulfills, such as improving patient health) and the exchange value (i.e., the commercial value, such as productivity gains) (Engeström 1987). Building on AT, we conceptualize IS implementation projects as a means to deal with the manifestations of these primary contradictions. In our cases, the PDMS were introduced to the activities to balance patient safety (i.e., use value) and efficiency of patient care (i.e., exchange value). Extending prior research, this paper shows that the concept of contradiction can be used as a conceptual tool to not only identify and analyze but also to theoretically explain different grounded root causes of post-implementation issues (Strong and Volkoff 2010).

\subsubsection{Contradictions Unfold Across Multiple Elements}

Looking at the patterns of the problematic interrelations, one novel contribution is that we found triads of conflicting elements, as opposed to the dyads that past research dealing with IS post-implementation issues has focused on, in

Table 5 Tool-mediated relationships that need to be addressed during HIS implementation

$\begin{array}{ll}\text { Activity system } & \begin{array}{l}\text { Tool-mediated } \\ \text { relationship }\end{array}\end{array} \begin{aligned} & \begin{array}{l}\text { Things to consider in order to recognize the potential for contradictions } \\ \text { and identify additional managerial interventions }\end{array} \\ & \begin{array}{l}\text { (1) Subject-Object } \\ \text { (How) will the HIS account for different perspectives on the object that } \\ \text { is individually or collectively approached within the activity system? } \\ \text { (How) will the HIS affect the relationship between the subjects of the } \\ \text { activity system? } \\ \text { (How) will the HIS account for the interpretation and/or evolved } \\ \text { implementation of (conflicting) rules that govern individual actions and } \\ \text { interactions towards the object of the collective activity? } \\ \text { (How) will the HIS account for evolved modes of task distribution that } \\ \text { govern action and interaction towards the object of the collective } \\ \text { activity? }\end{array}\end{aligned}$


terms of either the user (i.e., subject) and the IS (i.e., tool) or the IS and process requirements (i.e., rules and distribution of labor) (see e.g., Boudreau and Robey 2005; Berente et al. 2016; Oborn et al. 2011; Strong and Volkoff 2010). This finding indicates the need to broaden the scope of interrelations between the elements that define the context of HIS implementation to explain possible dysfunctionalities that emerge after implementation. Using the concept of activity systems, we identified contradictions within four constellations of rules, division of labor, subjects, and object that emerged after adding the HIS to the activity system and manifested as post-implementation issues, negatively affecting the functioning of the activity system and, thus, its outcome.

\subsubsection{Latent and Salient Contradictions can be a Root Cause of Post-implementation Issues}

This study reveals that HIS implementation risks facilitating the emergence of new manifestations of primary contradictions but also causes the manifestation of latent contradictions. The latent contradictions we identified were amplified by the newly implemented HIS and became salient only after the IS changed the relationship between the subjects and the object of the activity. Groleau et al. (2012) argues that these latent primary contradictions between commercial and professional poles (i.e., use and exchange value) embodied in the relationship between the subjects and the object may surface as salient contradictions once new means or methods are introduced. This study not only adds evidence to this finding, we also show that the opposition between use value and exchange value defines the interrelation between the tools employed and other elements of the activity system, such as the division of labor. The interplay between these elements and the tools used may mitigate the effect of these contradictions and prevent them from manifesting as problems. In the cases analyzed here, the flexibility of the paper tool created an interdependent, complementary duality and allowed a mode of task distribution to evolve that covered up the contradiction (cf. Wareham et al. 2014). The HIS, though it resembles the functionalities of the paper-based tool, had the potential to dissolve what Jay (2013, p. 137) refers to as the "latent organizational paradox," causing hitherto latent contradictions to manifest as post-implementation issues by managing contested perspectives regarding the object of the collective work differently. This may then cause already embodied latent contradictions to manifest as postimplementation issues. This again highlights that IS-related impositions not only emerge from the functionalities of the IS (Strong and Volkoff 2010) but are created by the dynamics of "the 'binding' of time-space" in activities (Giddens 1984). Thus, we answer the call for a better understanding of contextual complexities in IS research and further specify this call by emphasizing the need to analyze the wider historical trajectory of an activity in the context of all its elements and their relationships in order to make sense of post-implementation issues. At the same time, we show that an awareness of latent and salient contradictions in activity systems enables a better understanding of the post-implementation issues that may emerge in one context but not in another.

\subsubsection{Management Interventions Need to Target Multiple Elements}

Prior literature has already analyzed the effectiveness of several intervention strategies that aim to mitigate misalignments between an IS and users practices, such as workarounds (Boudreau and Robey 2005), the dynamic adjustment of practices (Berente et al. 2016), alignment across different disciplines (Oborn et al. 2011), and adaptations to technology (Wei et al. 2005). However, most extant research focuses on interventions affecting single elements of an activity system. We contribute to this research by showing that management interventions need to account for the complex interactions of all elements of an activity system. This corresponds to our finding that contradictions may often affect more than two elements of the activity system, and hence effective interventions geared to resolve those contradictions must account for this higher level of complexity. Accordingly, before choosing and implementing interventions, a sound understanding of the root causes of post-implementation issues is required (i.e., the contradiction within the activity system), which may not be limited to an IS and its users. Instead, our study shows that addressing post-implementation issues may require interventions beyond tackling the IS and user actions, such as interventions dealing with the division of labor or rules that govern the collective activity. Moreover, in terms of latent contradictions that are already inscribed within the activity prior to implementation, the case study also indicates that these contradictions tend to require interventions that focus on complementary elements of the activity system. However, identifying such contradictions is apparently difficult during daily work routines. In line with AT and other theories that conceptualize mediated human activity, elements that define an activity but are not in focus during IS implementation and are not (yet) causing issues, usually receive little attention (Riemer and Johnston 2013). However, implementing a new IS as a tool would most likely impact the complex interrelations among those elements. 


\subsubsection{Multiple Interventions may be Needed to Solve Contradictory Relationships}

Post-implementation issues that are linked to contradictions rooted in broader socioeconomic contexts, such as the conflict between use value and exchange value, are more difficult to resolve. In such cases, a single intervention may not be sufficient. Rather, multiple interventions geared toward addressing different elements simultaneously are often necessary to mitigate the issues associated with such contradictions. Thus, the combination of interventions across elements matters. The data also indicates that the element on which effective management interventions focus is always part of the contradiction that should be mitigated. Through using the concept of the activity system, this study contributes a theoretically grounded means of relating interventions to specific elements. This offers a foundation upon which further studies could analyze interventions, their interrelationships, and their effects more specifically, e.g., whether interventions geared toward subjects are better suited than interventions geared toward other elements to counter contradictions. Moreover, further research should focus on identifying the necessity and effects of complementary interventions.

\subsubsection{Avoidance of Contradictions by Finding Synergistic Solutions}

Finally, our findings indicate that it is possible to avoid contradictions related to divergent motives by combining the introduction of a new tool with changes in other elements of the activity system, either up-front or through interventions counterbalancing unintended contradictions. This topic relates to the argument that pursuing humanistic goals entails positive actions which, in turn, amplifies synergistic solutions (Sarker et al. 2019). As already mentioned, the humanistic goal of physicians and nurses was almost identical and related to improving patient health status. However, the motives (ensuring better data for diagnoses; securing more time to care for patients) and, consequently, the means of achieving this goal differed across the subject groups. Finding a synergistic solution involved securing both better data for diagnosis as well as more time for patient care, outcomes that should amplify each other and lead to even greater improvements in patient health status. Thus, even if motives diverge, it is often possible to identify a synergistic solution, rather than a solution involving a trade-off between motives.

\section{Summary of Implications}

By contributing a theoretically grounded investigation of contradictions and potential interventions, we also respond to the call for research on the sociotechnical complexities faced by HIS (Bittner and Leimeister 2014). We show that unawareness of potential complexities increases the emergence of post-implementation issues such as inefficiencies and resistance among key users, which jeopardizes the activity system's outcome. We hope that the application of $\mathrm{AT}$ and the framework developed motivates research to further improve the understanding of contradictions and the interventions needed to resolve them.

In sum, we demonstrate that the AT framework is a useful theoretical tool to identify often overlooked contradictions that are either newly created or that become salient in post IS-implementation phases, particularly if an IS is implemented within complex sociotechnical contexts such as healthcare. As an extension of prior AT-based research in IS (e.g., Karanasios and Allen 2013), we investigated in detail the rules and norms as well as the modes of task distribution that framed the healthcare activities we examined and that interacted with the implemented IS. In addition, we show that interventions that seek to resolve or mitigate these contradictions help stabilize the activity system in the post-implementation phase and facilitate the achievement of initial goals, namely improving patient health status.

\subsection{Implications for Practice}

The framework developed in this research draws attention to the wider context of individual action that shapes healthcare activities, particularly in terms of the complex mediating relationships between tools, rules, subjects, object, and the division of labor. Applied during implementation projects, the framework may facilitate the implementation of new HIS within healthcare activities. Ultimately, it may enable project teams to avoid unintended contradictions occurring between elements of the activity system.

Although awareness of the contradictions among elements of the activity system will help, practitioners should bear in mind that an important prerequisite to learning about an activity is to participate in that activity (Greig et al. 2012). Thus, attaining a deeper understanding of the interplay between the elements of an activity system may require IT professionals to occasionally participate in or at least observe activities that are or may be affected by the HIS. Practitioners should particularly focus on the triads identified in this research, as they can presumably be observed in practice. This should enable them to better understand the nexuses identified here, to anticipate 
contradictions, and to take corrective management interventions.

In line with this recommendation, the framework may also support the process identification and discovery phase of the business process management lifecycle (Recker and Mendling 2015). Identification of local and temporal variations to the established course of action - e.g., how different wards (local) deal with medication management in cases of emergency (temporal) - as well as sufficient understanding of the role of the tools employed is not only a prerequisite for HIS implementation but also necessary for redesigning business processes.

Furthermore, our data indicates that the subjects involved should share and integrate their perspectives about the activity system in which the HIS will operate and agree on how to make HIS a legitimate and supportive part of the activity system without creating or amplifying contradictions. Concretely, to avoid problems after enrolling new tools, participants involved in HIS implementation should share their interpretation of both the legacy tool and its successor as well as their role in the activity system and should consider the effect of further elements such as tools, rules/norms and a division of labor early on.

Practitioners may also wish to employ cooperative strategies such as prototyping if users and IT professionals are mutually involved (Mogensen 1992). Prototyping may raise issues and shift questions from subject-object interactions toward the rather invisible IS-mediated characteristics of collective activities. Moreover, best practices and approaches like business process management and the "MindMerger" (Bittner and Leimeister 2014) could benefit from methods that place an emphasis on the collective nature of human activity, such as "expansive visibilization" (Engeström 1999). Expansive visibilization focuses on the incidents and incremental innovations in everyday work actions in order to make these incidents and innovations visible and to understand how work activities evolve over time. Thus, expansive visibilization may help increase the understanding of the role of current and new tools within activity systems and may help to implement a new IS without unintentionally jeopardizing the functionality of activity systems.

\subsection{Limitations and Future Research}

We acknowledge the limitations of our study to provide the frame of reference for the interpretation of our findings. First, the empirical data analyzed in this research derives from only two case studies at a single site. Thus, the activity theoretical perspective still needs to demonstrate its explanatory power in other settings (Lee and Baskerville 2003). While a single site, i.e., one hospital, has advantages because certain context factors such as the overall corporate strategy and corporate policies are identical for both cases, thus preventing additional influence factors on our findings, using different sites improves the generalizability of findings.

Second, the time frame for data collection was restricted. We acknowledge that activity systems are shaped over space and time. Therefore, we cannot rule out the possibility of additional post-implementation issues following data collection. However, as we predominantly focused on contradictions and interventions occurring in the post-implementation phase, which we observed over time, this circumstance should not have biased our findings too much. Nevertheless, observing the entire implementation and post-implementation phase might lead to a deeper understanding of the causes of contradictions and effects of interventions in the long run.

Third, the number of interviews conducted was limited, some of the interviewees did not want to be recorded, and only one researcher monitored the rollout. Further research employing additional multiple and longitudinal case studies in other settings or quantitative studies may increase the confidence in the mechanisms discussed below. Fourth, we observed contradictions and the interventions dealing with these contradictions and found that interventions are always bound to certain elements of the activity system. Thus, we observed interventions related to certain contradictions rather than those related to elements. This allowed for the identification of the combination of interventions appropriate to tackle a certain contradiction. However, this focus prevented us from observing whether one intervention is more appropriate than another. Future research could focus on interventions geared toward subjects and study whether those interventions are more appropriate to tackle contradictions than interventions geared toward the object.

Fifth, the healthcare context is often characterized by a conflict between humanistic and instrumental goals where instrumental goals such as efficiency often dominate humanistic goals. In one of our cases, we observed both goals and found that the two goals were insufficiently achieved with the legacy system. However, as potential conflicts between both goals did not surface in the postimplementation phase we observed, we observed only that the implementation of the new HIS resolved the issue of insufficient achievement of the two goals. We consider this a promising avenue for future research because the healthcare context, in particular, is characterized by conflicts between different goals, such as the profitability of a hospital (instrumental goal) and patient care (humanistic goal). Thus, although previous research has characterized the relationship between these goals as a trade-off resolved through compromise, and has suggested that instrumental goals often dominate humanistic goals (Sarker et al. 2019), 
one of our findings show that appropriate interventions made it possible to identify a synergistic solution for different motives related to the humanistic goal of patient health status. Finding a synergistic solution might also be possible for different goals; indeed there could be a recursive link between instrumental and humanistic goals, and pursuing humanistic goals may potentially positively influence the achievement of instrumental goals which, in turn, would positively influence the achievement of humanistic goals (Sarker et al. 2019). Future research that explores such linkages that go beyond simple trade-off considerations could advance the understanding of synergistic solutions.

Sixth, the theoretical ideas developed in this paper derive from analyses of HIS implementation case studies. However, the framework is potentially also applicable to IS implementation in other contexts, such as professional organizations (Diefenbach and Sillince 2011). As is the case in hospitals, professional organizations are characterized by activities dominated by complementary professions organized into distinct formal and informal hierarchies. Future research may demonstrate how the suggested framework can be adapted to increase the understanding of the role of IS for implementations in governmental agencies, institutions of higher education, consulting and accounting firms, etc.

\section{Conclusion}

This article offers theoretical and empirical evidence that deeper investigation of contradictions and interventions within IS-mediated activity systems can provide vital insights into how IS implementations can be improved. Based on in-depth analysis of two case studies in the healthcare context, we show that contradictions among social and technical elements constrain the achievement of the goals that organizations aim to achieve through the implementation of a new IS.

Our findings indicate that the "classic" focus on the relationship between users and a new IS is not sufficient. Contradictions also concern further elements of the activity system, like rules and the division of labor. In fact, not only dyads but also triads of elements are typically involved when new contradictions arise. Not fully identifying and understanding the complex mechanisms within the activity system constrains the effectiveness of counterbalancing interventions and may lead to new contradictions.

We show how latent contradictions may become salient due to the implementation of a new IS. In such cases, latent contradictions are already present in an activity system prior to the introduction of a new IS, but they are hidden, e.g., by flexibilities available in the old system or by adapted work practices and workarounds. However, after the new IS is implemented, these latent contradictions become apparent and negatively affect the outcomes of the activity system. This type of contradiction is widely overlooked in theory and practice.

The interventions used to counterbalance contradictions, which we observed in the cases reported here, were all geared toward directly impacting specific elements of the activity system, rather than affecting relationships between elements. We draw the conclusion that applying combinations of interventions across several elements might be more effective than singular interventions to counterbalance contradictions. Thus, we suggest that combinations of interventions going beyond the new IS or the user that involve multiple elements of the activity system will lead to better outcomes. In addition, we find that combinations of interventions may be able to not just balance contradictions by providing a compromise but may even enable synergistic solutions. The latter goes beyond repairing or restoring the status quo activity system, aiming instead to improve and create a new activity system that facilitates better outcomes.

Funding Open Access funding enabled and organized by Projekt DEAL.

Open Access This article is licensed under a Creative Commons Attribution 4.0 International License, which permits use, sharing, adaptation, distribution and reproduction in any medium or format, as long as you give appropriate credit to the original author(s) and the source, provide a link to the Creative Commons licence, and indicate if changes were made. The images or other third party material in this article are included in the article's Creative Commons licence, unless indicated otherwise in a credit line to the material. If material is not included in the article's Creative Commons licence and your intended use is not permitted by statutory regulation or exceeds the permitted use, you will need to obtain permission directly from the copyright holder. To view a copy of this licence, visit http://creativecommons. org/licenses/by/4.0/.

\section{References}

Abouzahra M, Guenter D, Tan J (2015) Integrating information systems and healthcare research to understand physicians' use of health information systems: a literature review. In: Paper presented at the international conference on information systems, Fort Worth

Agarwal R, Gao G, DesRoches C, Jha AK (2010) Research commentary: the digital transformation of healthcare: current status and the road ahead. Inform Sys Res 21(4):796-809

Albert D, Kreutzer M, Lechner C (2015) Resolving the paradox of interdependency and strategic renewal in activity systems. Acad Manag Rev 40(2):210-234

Allen DK, Brown A, Karanasios S, Norman A (2013a) How should technology-mediated organizational change be explained? A comparison of the contributions of critical realism and activity theory. MIS Q 37(3):835-854 
Allen DK, Karanasios S, Norman A (2013b) Information sharing and interoperability: the case of major incident management. Europ J Inf Syst 23(4):418-432

Allwood CM, Selart M (eds) (2010) Decision making: social and creative dimensions. Springer, Dordrecht

Ammenwerth E, Iller C, Mahler C (2006) IT-adoption and the interaction of task, technology and individuals: a fit framework and a case study. BMC Med Inform Decis Mak 6:3

Avgerou C (2001) The significance of context in information systems and organizational change. Inf Syst J 11(1):43-63

Bardhan IR, Thouin MF (2013) Health information technology and its impact on the quality and cost of healthcare delivery. Decis Support Syst 55(2):438-449

Benbya H, Nan N, Tanriverdi H, Yoo Y (2020) Complexity and information systems research in the emerging digital world. MIS Q 4(1):1-17

Berente N, Lyytinen K, Yoo Y, King JL (2016) Routines as shock absorbers during organizational transformation: integration, control, and NASA's enterprise information system. Organ Sci 27(3):551-572

Bittner EAC, Leimeister JM (2014) Creating shared understanding in heterogeneous work groups: why it matters and how to achieve it. J Manag Inf Syst 31(1):111-144

Boudreau M-C, Robey D (2005) Enacting integrated information technology: a human agency perspective. Organ Sci 16(1):3-18

Cole M, Engeström Y (1993) A cultural historic approach to distributed cognition. In: Salomon G (ed) Distributed cognitions: psychological and educational considerations. Cambridge University Press, Cambridge, pp 1-46

Cresswell K, Sheikh A (2013) Organizational issues in the implementation and adoption of health information technology innovations: an interpretative review. Int $\mathrm{J}$ Med Inform 82(5):e73-86

Cresswell KM, Bates DW, Sheikh A (2013) Ten key considerations for the successful implementation and adoption of large-scale health information technology. J Am Med Inform Assoc 20(e1):e9-e13

Diefenbach T, Sillince JAA (2011) Formal and informal hierarchy in different types of organization. Organ Stud 32(11):1515-1537

Dwivedi YK, Wastell D, Henriksen HZ, De' R, (2015) Guest editorial: grand successes and failures in IT: Private and public sectors. Inf Syst Front 17(1):11-14

Eisenhardt KM (1989) Building theories from case study research. Acad Manag Rev 14(4):532-550

Engeström Y (1987) Learning by expanding. An activity-theoretical approach to developmental research. Orienta-Konsultit, Helsinki

Engeström Y (1999) Expansive visibilization of work: an activitytheoretical perspective. Comput Support Coop Work 8(1):63-93

Engeström Y (2001) Expansive learning at work: toward an activity theoretical reconceptualization. J Edu Work 14(1):133-156

Engeström Y, Punamäki R-L (1999) Perspectives on activity theory. Cambridge University Press, Cambridge

Fichman RG, Kohli R, Krishnan R (2011) Editorial overview: the role of information systems in healthcare: current research and future trends. Inf Syst Res 22(3):419-428

Fretschner R, Bleicher W, Heining A, Untertl K (2001) Patient data management systems in critical care. J Am Soc Nephrol 1(suppl 1):83-86

Gerring J (2008) Case study research: principles and practices. Cambridge University Press, Cambridge

Giddens A (1984) The constitution of society. University of California Press, Berkeley

Goh JM, Gao G, Agarwal R (2011) Evolving work routines: adaptive routinization of information technology in healthcare. Inf Syst Res 22(3):565-585
Greig G, Entwistle VA, Beech N (2012) Addressing complex healthcare problems in diverse settings: insights from activity theory. Soc Sci Med 74(3):305-312

Groleau C, Demers C, Lalancette M, Barros M (2012) From hand drawings to computer visuals: confronting situated and institutionalized practices in an architecture firm. Organ Sci 23(3):651-671

Heeks R (2006) Health information systems: failure, success and improvisation. Int J Med Inform 75(2):125-137

Jay J (2013) Navigating paradox and innovation in hybrid organizations. Acad Manag J 56(1):137-159

Karanasios S, Allen D (2013) ICT for development in the context of the closure of Chernobyl nuclear power plant: an activity theory perspective. Inf Syst J 23(4):287-306

Karanasios S, Allen D (2014) Mobile technology in mobile work: contradictions and congruencies in activity systems. Europ J Inf Syst 23(5):529-542

Kilsdonk E, Peute LW, Riezebos RJ, Kremer LC, Jaspers MW (2016) Uncovering healthcare practitioners' information processing using the think-aloud method: from paper-based guideline to clinical decision support system. Int J Med Inform 86:10-19

Klauber J, Geraedts M, Friedrich J, Wasem J (2010) KrankenhausReport 2011: Qualität durch Wettbewerb. Schattauer GmbH

Kuutti K (1999) Activity theory, transformation of work, and information systems design. In: Engeström Y, Miettinen R, Punamäki-Gitai R-L (eds) Perspectives on activity theory: learning in doing: social, cognitive and computational perspectives. Cambridge University Press, Cambridge, pp 360-376

Lee AS, Baskerville RL (2003) Generalizing generalizability in information systems research. Inf Syst Res 14(3):221-243

Lluch M (2011) Healthcare professionals' organisational barriers to health information technologies: a literature review. Int J Med Inform 80(12):849-862

Maxwell JA (2013) Qualitative research design: an interactive approach, 3rd edn. Sage, Thousand Oaks

Miles MB, Huberman AM (1994) Qualitative data analysis: an expanded sourcebook. Sage, Thousands Oaks

Mintzberg H (1979) The structuring of organizations. Prentice-Hall, Englewood Cliffs

Mogensen P (1992) Towards a provotyping approach in systems development. Scand J Inf Syst 4(1):31-53

Oborn E, Barrett M, Davidson E (2011) Unity in diversity: electronic patient record use in multidisciplinary practice. Inf Syst Res 22(3):547-564

Poon EG, Blumenthal D, Jaggi T, Honour MM, Bates DW, Kaushal R (2004) Overcoming barriers to adopting and implementing computerized physician order entry systems in U.S. hospitals. Health Aff 23(4):184-190

Recker J, Mendling J (2015) The state of the art of business process management research as published in the BPM conference. Bus Inf Syst Eng 58(1):55-72

Riemer K, Johnston RB (2013) Rethinking the place of the artefact in IS using Heidegger's analysis of equipment. Europ J Inf Syst 23(3):273-288

Rohner P (2013) Identity management for health professionals. Bus Inf Syst Eng 5(1):17-33

Sarker S, Chatterjee S, Xiao X, Elbanna A (2019) The sociotechnical axis of cohesion for the IS discipline: its historical legacy and its continued relevance. MIS Q 43(3):695-720

Seo M-G, Creed WD (2002) Institutional contradictions, praxis, and institutional change: a dialectical perspective. Acad Manag Rev 27(2):222-247

Sharma L, Chandrasekaran A, Boyer KK, McDermott CM (2016) The impact of health information technology bundles on hospital performance: an econometric study. J Oper Manag 41:25-41 
Smith WK, Lewis MW (2011) Toward a theory of paradox: a dynamic equilibrium model of organizing. Acad Manag Rev 36(2):381-403

Strong DM, Volkoff O (2010) Understanding organization: enterprise system fit: a path to theorizing the information technology artifact. MIS Q: $731-756$

Strong DM, Volkoff O, Johnson SA, Pelletier LR, Tulu B, Bar-On I, Trudel J, Garber L (2014) A theory of organization-EHR affordance actualization. J Assoc Inf Syst 15(2):2

Walsham G (1995) Interpretive case studies in IS research: nature and method. Europ J Inf Syst 4(2):74-81

Walsham G (2006) Doing interpretive research. Europ J Inf Syst 15(3):320-330

Wareham J, Fox PB, Cano Giner JL (2014) Technology ecosystem governance. Organ Sci 25(4):1195-1215
Weeger A, Gewald H (2015) Acceptance and use of electronic medical records: an exploratory study of hospital physicians' salient beliefs about HIT systems. Health Syst 4(1):64-81

Wei H-L, Wang ETG, Ju P-H (2005) Understanding misalignment and cascading change of ERP implementation: a stage view of process analysis. Europ J Inf Syst 14(4):324-334

Williams R, Pollock N (2012) Research commentary - moving beyond the single site implementation study: how (and why) we should study the biography of packaged enterprise solutions. ISR 23(1):1-22

Yaraghi N (2015) An empirical analysis of the financial benefits of health information exchange in emergency departments. J Am Med Inform Assoc 22(6):1169-1172

Yin RK (2009) Case study research: design and methods. Sage, Thousand Oaks 